\title{
China plans 'hybrid' embryonic stem cells
}

\section{Alison Abbott \& David Cyranoski}

The controversy surrounding research on human embryonic stem (ES) cells now extends to the world's most populous nation.

Chinese scientists have revealed that they have transferred nuclei from human cells into rabbit eggs stripped of their own chromosomes. They hope to use the resulting embryos to generate ES cells for research into regenerative medicine. Previously, only one other group - at the biotech company Advanced Cell Technology (ACT) in Worcester, Massachusetts - had admitted to transferring human cells into the eggs of another species in this way.

ES cells may allow the production of specialized cells and tissues to replace those lost to disease - neurons to treat sufferers of Parkinson's disease, for example, or cardiac muscle for heart-attack victims. If the embryos that provide these cells are created by the nuclear-transfer cloning technique used to create Dolly the sheep, the tissues would be genetically identical to the patient, avoiding the problem of immune rejection.

But this 'therapeutic cloning' requires eggs, and human ones are in extremely short supply. Three years ago, ACT announced that it had devised a way around the problem - replacing human eggs with those of cows, which can be obtained from cattle ovaries collected in abattoirs. The announcement provoked intense controversy, however, with many commentators expressing distaste at the idea of cross-species nuclear transfer.

This month, Chen Xigu of Sun Yat-Sen University of Medical Sciences in Guangzhou told newspapers that his research group is working along the same lines. Chen and colleagues removed the chromosomes from rabbit eggs and replaced them with the nuclei of skin cells from a seven-year-old boy. In some of the 100 or so successful nuclear transfers, an embryo developed to the morula stage - the compact ball of cells that forms after about three days of embryonic development.

Before ES cells can be isolated from human embryos, they need to develop beyond this stage to form a hollow, fluidfilled structure called a blastocyst. Chen has not yet been able to coax his embryos into developing this far, but he is optimistic of success.

However, Jose Cibelli, who leads the ACT therapeutic cloning team, says that growing the blastocysts will not be easy. "There is a big difference between getting a nice morula stage and the next step," he says. Cibelli's team has managed to create blastocysts, but only at a low rate. They take ten days or so to develop, compared to five or six days in normal human embryos.

Chen plans to submit his work for publi-

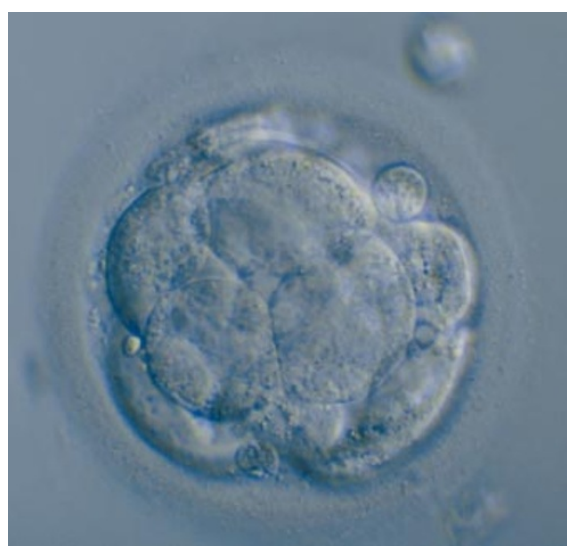

Key point: human embryos must develop beyond the morula stage before stem cells can be isolated.

cation by the end of this year, but the ACT team does not intend to publish. "We are not happy with our results, which are inconsistent, and we are not happy with the general quality of the blastocysts," says Cibelli.
Chen's work has attracted criticism in China. "Some people in China are against me doing this research," he admits. And pressure is increasing to introduce legislation.

Zhu Chen, vice-president of the Chinese Academy of Sciences and director of the publicly-funded Chinese National Human Genome Center in Shanghai, has been campaigning for tighter ethical regulation of biomedical research. After reading newspaper reports about Chen Xigu's work two weeks ago, he called on the National Centre for Biotechnology Development, part of the Chinese Ministry of Science and Technology, to propose ethical guidelines for genomic and stem-cell research. "It is of great importance for a large country like China for this kind of work to be under strict regulation," he says.

Ming-Wei Wang, a veteran of Shanghai's biotech industry and vice-chairman of Ancile Pharmaceuticals in San Diego, says the regulation of biomedical research in China is patchy, even where laws are in place.

\section{Stamp booklet has physicists licked}

Erica Klarreich, London

British physicists are taking issue with a Royal Mail brochure, published in association with six new postage stamps, which suggests that quantum physics could help to explain the paranormal.

The brochure, part of a presentation package to commemorate the centenary of the Nobel prizes, will be available at 18,000 post offices from 2 October.

The material at issue was written by Brian Josephson, a professor at the University of Cambridge, who a Nobel prize in 1973 for his work on superconductors. The entry says that developments in quantum physics, combined with information technology, "may lead to an explanation of processes still not understood within conventional science, such as telepathy - an area in which Britain is at the forefront of research".

Josephson gave his name to the Josephson effect, which describes the flow of current between two pieces of superconducting

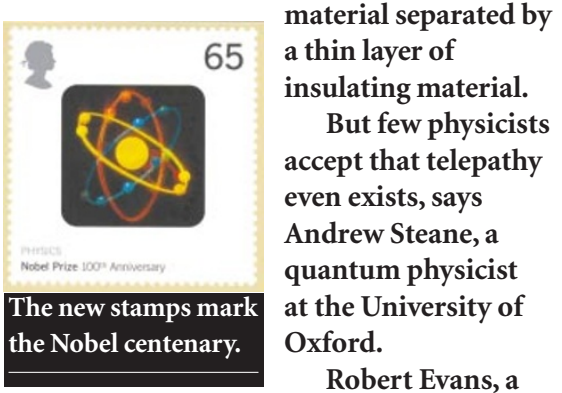

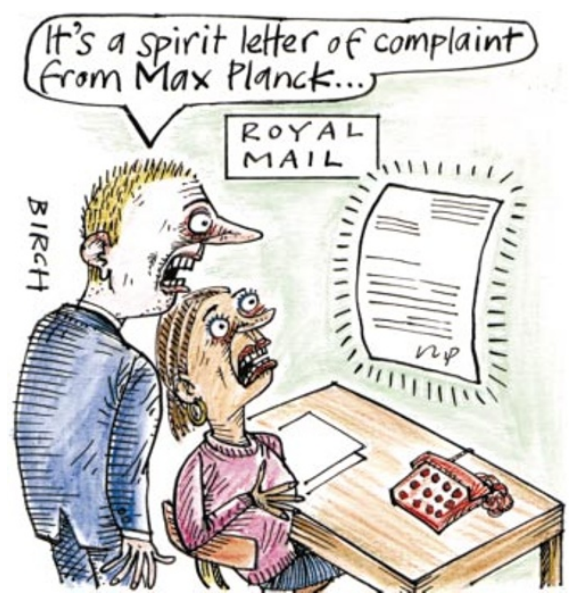

physicist at the University of Bristol, says he is "very uneasy" about something from the Royal Mail saying quantum physics has something to do with telepathy," he says.

Kathryn Hollingsworth, a spokeswoman for the Royal Mail, says: "If it transpires that what he's suggesting doesn't have a scientific basis, perhaps we should have checked that," she says. "But if he has won a Nobel prize for his work, that should give him some credibility."

Josephson wrote the paragraph at the Royal Mail's invitation. A number of theories, he says, are helping to explain "how a more detailed understanding of paranormal phenomena may emerge from a better understanding of quantum mechanics". 